\title{
PERTEMPURAN KASIRO-SUNGAI PINANG BATANG ASAI MENGHADAPI AGRESI MILITER BELANDA II DI KEWEDANAAN SAROLANGUN 1948-1949
}

\author{
Supian \\ Dosen Departemen Sejarah, Seni dan Arkeologi, Universitas Jambi \\ Email: supian.ramli@unja.ac.id \\ Lagut \\ Mahasiswa Departemen Sejarah, Seni dan Arkeologi, Universitas Jambi \\ Email:lagutbakaruddin@gmail.com
}

\begin{abstract}
ABSTRAK
Tujuan penulisan artikel ini adalah untuk melihat pola perjuangan kemerdekaan di Keresidenan Jambi Hulu tepatnya di daerah Batang Asai Kewedaaan Sarolangun dalam menghadapi agresi militer Belanda. Perang kemerdekaan di Keresidenan Jambi tidak hanya dirasakan oleh penduduk ibu kota Keresidenan atau Kewedanaan namun di berbagai daerah Pedalaman seperti di pedalaman Kewedanaan Sarolangun tepatnya di daerah Batang Asai. Metode yang digunakan dalam penelitiaan ini adalah metode historis yang terdiri dari empat tahap yaitu Heuristik, Kritik, Interprestasi, dan Historiografi. Perlawanan yang dilakukan oleh masyarakat dan para pejuang di Batang Asai merupakan perjuangan yang dilakukan semata-mata demi mempertahankan martabat bangsa.
\end{abstract}

Kata Kunci: Revolusi Kemerdekaan, Batang Asai, Kasiro-Sungai Pinang

\begin{abstract}
The purpose of writing this article is to see the struggle for independence in the Upper Jambi Residency precisely in the Batang Asai area of Sarolangun Authority. The war of independence in the Jambi Residency was not only felt by residents in the capital of the Residency or in the region, but in various rural areas such as in the Saroalngun village in precisely the Batang Asai area. The method used in this research was a historical method consisting of four stages namely Heuristic, Critical, Interpretation, and Historiography. The resistance carried out by the people and fighters in Batang Asai is a struggle carried out solely for the sake of maintaining the dignity of the nation and promoting independence.
\end{abstract}

Keyword: Independence Revolution, Batang Asai, Kasiro-Sungai Pinang

\section{PENDAHULUAN}

Pada tangal 17 Agustus 1945 tepat pukul 10.00 Wib di Pegangsaan Timur No 56 Jakarta dibacakanlah proklamasi kemerdekaan oleh Sukarno dan didampingi Muhammad Hatta. Ketika proklamasi kemerdekaan telah dibacakan 
PERTEMPURAN KASIRO- SUNGAI PINANG BATANG ASAI MENGHADAPI AGRESI

MILITER BELANDA II DI KEWEDANAAN SAROLANGUN 1948-1949

(Supian, Lagut)

menandakan bahwa Indonesia telah merdeka. Dengan kata lain lahirnya "Indonesia" (Sudirman: 2014). NKRI sudah terbentuk namun perjuangan bangsa Indonesia belum usai sejak terbentuknya Negara Kesatuaan Republik Indonesia pada tanggal 17 Agustus 1945 muncul berbagai konflik di berbagai daerah di Indonesia. Konflik ini muncul antara para pejuang kemerdekaan Indonesia dengan pihak penjajah yang ingin menguasai kembali Indonesia konflik muncul dengan pihak penjajah (Belanda) melakukan serangan Agresi terhdap daerah- daerah di Indonesia dengan berusaha mendudukinya kembali.( Sudirman, 2014)

Penyebaran berita proklamasi ke berbagai pelosok daerah di Indonesia mengalami kesulitan karena keterbatasan alat komunikasi dan tranportasi hal inilah yang membuat proklamasi kemerdekaan tidak diketahui serentak di Indonesia, namun proklamasi berangsur-angsur sampai kepada rakyat dari kota sampai ke pelosok pedesaan di Indonesia (Musyrifah, 2010). Berita proklamasi kemerdekaan masuk wilayah Sumatera dibawa oleh Gubernur Sumatera pertama yaitu Tengku Moh Hasan pada saat itu Sumatera merupakan satu dari delapan Provinsi di Indonesia yang beribukota di Medan yang membawahi sebelas Keresidenan yaitu: Aceh, Sumatera Timur, Tapanuli, Sumatera Barat, Riau, Jambi, Palembang, Bangka Belitung, Bengkulu, dan Lampung ( Lindayanti: 2014)

Pada tanggal 18 April 1946 Komite Nasional Indonesia Sumatera bersidang di Bukittinggi memutuskan Provinsi Sumatera terdiri dari tiga Sub Provinsi yaitu Sub Provinsi Sumatera Utara, Sumatera Tengah dan Sumatera Selatan. Untuk Provinsi Sumatera Tengah terdiri dari Keresidenan Jambi, Keresidenan Riau, dan Kereisdenan Sumatera Barat yang berpusat di Kota Bukittinggi (Pemrov Jambi, 2013). Keresidenan Jambi yang memiliki 2 Kabupaten dan 1 kota Praja yakni Kabupaten Batanghari, Kabupaten Merangin, dan Kota Praja Jambi. Kabupaten Merangin atau disebut sebagai Kabupaten Jambi Hulu membawahi beberapa Kewedanaan seperti Kewedanaan Sarolangun, Kewedanaan Bangko, Kewedanaan Bungo dan Kewedananan Tebo. Kemudian Kabupaten Batangahari disebut dengan istilah Kabupaten Jambi Hilir dengan membawahi Kewedanaan Muaro Tembesi, Kewedanaan Jambi Luar Kota, Kewedanaan Kuala Tungkal dan Kewedanaan Muara Sabak. ( Yulia: 2017: 23) 
Gubernur Sumatera Tengah Nasrun dan Rasiden Jambi Inu Kertapati telah membagi Kabupaten Merangin menjadi beberapa Kewedanaan dan Kabupaten Batanghari juga beberapa Kewedanaan. Kabupaten Merangin yang berpusat di Bangko dan Batanghari yang berpusat di Kenali Asam (Sangkara: 2017). Kajian ini akan membahas perjuangan kemerdekaan di daerah Kabupaten Merangin tepatnya di Batang Asai daerah Keresidenan Jambi bagian hulu. Kewedanaan Sarolangun sebelah timur berbatasan dengan Kewedanaan Rawas (Keresidenan Palembang), sebelah barat berbatasan dengan Kewedanaan Bangko, sebelah utara berbatasan dengan Kewedanaan Muara Tembesi dan sebelah selatan berbatasan dengan Keresidenan Bengkulu. Kewedanana Sarolangun terdiri dari bebrapa daerah marga seperti Batang Asai, Pelawan, Limun, Cermin Nan Gedang, Mandiangin, Pauh dan Batin VII.

Bebicara Batang Asai masa kemerdekaan, Batang Asai merupakan salah satu daerah di Kewedanaan Sarolangun yang terdiri dari beberapa pemerintahan dusun (setingkat desa pada saat ini) di antaranya Kasiro, Sungai Pinang, Batu Empang, Bukit Sulah, Datuk Nan Duo, Muaro Cuban, Muaro Pemuat, Muaro Air Dua, Lubuk Bangkar, Padang Jering, Sungai Baung, Sungai Bemban, Sungai Keradak, Raden Anom, Rantau Panjang, Bukit Sulah, Bukit Berantai, Padang Jering, Paniban Baru, Pekan Gedang, Pulau Gadang, Pulau Salak Baru, dan tambak Ratu. Seputar sejarah perjuangan kemerdekaan di daerah Jambi sudah banyak karya yang membahas ini seperti dalam tulisan Syura Aulia Pad Jurusan Ilmu Sejarah Universitas Jambi mengenai "Rakyat Bungo Dalam Perang Kemerdekaan (1945-1949) "tulisan ini merupakan sebuah Skripsi juga membahas seputar revolusi kemerdekaan tepatnya di Bungo yang kala itu masuk ke Kabupaten Merangin (Syura:2017) Untuk daerah Kewedanaan Sarolangun sekitarnya juga minim tulisan-tulisan sejarawan seputar perang kemerdekaan. Perang kemerdekaan yang terjadi di daerah pedalaman Jambi tidak kalah menarik untuk ditulis banyak kejadian-kejadian besar daerah pedalaman dalam mempertahankan kemerdekaan pada masa itu. 
PERTEMPURAN KASIRO- SUNGAI PINANG BATANG ASAI MENGHADAPI AGRESI

MILITER BELANDA II DI KEWEDANAAN SAROLANGUN 1948-1949

(Supian, Lagut)

\section{METODE}

Metode yang digunakan dalam penelitiaan ini adalah metode Historis atau metode sejarah. Menurut Kuntowijoyo dalam penelitian sejarah terdiri dari empat tahapan yakni Heuristik, Kritik Sumber, Interpretasi, dan Historiografi (Kuntowijoyo: 2013). Heuristik merupakan tahapan pertama yakni pengumpulan sumber (Suhartono: 2014. Untuk dalam tahapan ini penulis menemukan sumbersumber sejarah di berbagai instansi di Provinsi Jambi seperti Dinas Perpustakaan dan Arsip Daerah Provinsi Jambi, Perpsutakaan Universitas Jambi, Perpustakaan Jurusan Sejarah Seni dan Arkeologi FKIP UNJA, Laboraturium Ilmu Sejarah Universitas Jambi, dan koleksi buku sumber pribadi.

Langkah selanjutnya yaitu kritik sumber yang dimaksud kritik sumber adalah mengklasifikasikan sumber sejarah sebagai bahan penulisan sejarah, dengan kata lain sumber sejarah harus diklasifikasikan dan diintentifikasikan. Dalam tahapan ini dibedakan menjadi dua yani kritik Internal dan Kritik Eksternal (Suhartono: 2014).

Tahapan berikutnya adalah interpretasi atau disebut penafsiran sumber sejarah. Pada tahapan ini penulis melakuakn pencermatan terhadap data-data hasil dari kritikan dan mengabungkan antara data satu dengan data yang lainya. Kemudian tahapan terahir adalah historiografi atau tahap penulisan.

\section{HASIL DAN PEMBAHASAN}

\section{Revolusi Kemerdekaan di Keresidenan Jambi}

Kekalahan sekutu dari tentara Jepang dalam perang pasifik atau dikenal dengan perang Timur Raya pada tahun 1941, Jepang segera mengambil alih kekuasaan dari tangan Belanda kemudian berkuasa di Indonesia selama 3.5 tahun. Tepat pada tangal 17 Agustus 1945 dua hari setalah Jepang bertekuk lutut dan dikalahkan oleh tentara sekutu dalam perang Pasifik, Sukarono dan Muhammd Hatta atas nama bangsa Indonesia memproklamirkan Kemerdekaan Indonesia. Kemudian Revolusi fisik yang berlangsung lima tahun terhitung semenjak Indonesia merdeka dan berakhir pengakuaan kedaulatan oleh Belanda pada tahun 1950 (Faisal: 2017.10) 
Menururt Prof Faisal Ismail negara Indonesa yang dimaksud adalah wilayah bekas jajahan Hindia Belanda dari abad ke 17 sampai abad ke 20 salah satu daerah di Pulau Sumatera adalah Jambi (Faisal: 2017). Selama 39 tahun kekuasan Hindia Belanda bercokol di Jambi pasca wafatnya Sultan Taha Saifuddin dan pemerintahan Hindia Belanda di Jambi berahir pada tahun 1942 dengan digantikan dengan pemerintahan Militer Jepang (Bambang:1979). Kemerdekaan yang berlangsung pada tangal 17 Agustus 1945 dan baru diketahui masyrakat Jambi pada tangal 18 Agustus 1945 yang disampaikan oleh A.K Gani kepada R.Sudarsono pemimpin buruh pertambangan minyak yang ada di Jambi (Dewan Pimpinan Cabang Legium Vetran RI:2019). Kemudian pada tanggal 20 Agustus 1945 informasi kemerdekaan sudah menyebar luas di kalangan masyarakat Jambi kemudian tokoh Jambi Abdullah Kartawirna menyebarkan kepada para pemuda di Jambi untuk segera mengibarkan bendera merah puth di seluruh instansi pada Keresidenan Jambi.

Pada masa revolusi Belanda melakukan ageresi yang pertama pada tanggal 21 Juli 1947 hal ini menimbulkan rekasi keras dan hebat dari dunia. Pada tanggal 30 Juli 1947 Pemerintahan India dan Australia mengusulkan agar masalah Indonesia dimasukan ke dalam daftar keamanan. Kemudian dewan keamanan melakukan perdebatan masalah Indonesia akhirnya menerima persetujuaan Amerika untuk menghentikan permusuhan dilakukan komisi jasa baik (Marwati dan Nugroho, 2011).

Perjuangan pada daerah Jambi perlu diperkuat dari Jambi Hulu sampai ke Kuala Tungkal dan semua perusahaan vital seperti tambang minyak, perusahaan listrik, dan sebagianya dikuasai militer dengan komandan Abunjani. Untuk pabrik senjata dalam menunjang perjuangan rakyat di daerah Bajubang dibangun pabrik senjata dengan pimpinan Mayor Darko. Strategi pertahanan dilakukan dengan Keresidenan Jambi dan Kewedanaan Kerinci (Dewan Harian Daerah Angkatan 45: 1991).

Di tengah-tengah menghdapai serangan Militer Belanda di Keresidenan Jambi pada bulan Juni 1948 Sukarno dan Hatta berkunjung ke Jambi. Kunjunagan pertama Sukarno ke Jambi disertai Rapat Umum yang dihadiri oleh masyrakat di berbagai pelosok Keresidenan Jambi. Sukarno Mengajak untuk 
PERTEMPURAN KASIRO- SUNGAI PINANG BATANG ASAI MENGHADAPI AGRESI

MILITER BELANDA II DI KEWEDANAAN SAROLANGUN 1948-1949

(Supian, Lagut)

berjuang bersama dalam mewujudkan kedaulatan Negara Kesatuaan Republik Indonesia (Dewan Harian Daerah Angkatan 45, 1991).

Pada tanggal 21 Juli 1947 TNI divisi VIII Garuda Sriwijaya (Subkoss) menysun struktur organisasi di antaranya: Brigade Garuda Merah/Sub Teritorial Palembang (STP) dengan komandanya Letkol Utoyo, Brigade Garuda Putih Sub Teritorial Djambi (STD) Komandnaya Letkol Abunjani, Brigade Garuda Hitam Sub Teritorial Lampung dengan Komandan Letkol Syamaun Gaharu, Brigade Garuda Emas dengan komandan Letkol Berlian, dan Brigade Garuda Emas dengan Komandan Letkol Hsan Kasim ( Suwandi.2002).

Kemudian pemerintahan pusat melanjtkan perundingan Indonesia Belanda atas persetujuan Renlive. Mr. Moh. Roem diangakat sebagai delegasi Republik Indonesia dan dipihak Belanda diwakili oleh Abdulkadir.tahun 1948 merupakan agresi militer Belanda II yang dilancarkan untuk Indonesia dalam menghadapi agresi militer belanda II Pemerintah melalui menteri pertahanan membentuk Markas Besar di Jawa dikenal dengan Markas Besar Djawa ( MBKD) dan Sumatera dikenal dengan Markas Besar Sumatera ( MBKS) ( Marwati dan Nugroho, 2011).

Untuk STD (Sub Teritorial Djambi) dibawah TNI Sub Komendemen Sumatera Selatan (Subkoss) dengan komandan Kolonel Abunjani.Untuk memprkuat jajaran TNI STD diebntuklah tiga Batalion yang terdiri dari Batalyon I Merangin dengan komandan Letnam Kolonel Harun Sohar, Batalyon II Jambi dengan Komandan Mayor Z, Marzuki, Batalyon III Tanah Minyak dengan komandan mayor Selamat (Harian Daerah Angkatan 45, 1991).

\section{Sambutan Kemerdekaan di Kewedanaan Sarolangun dan Sekitaranya}

Sarolangun merupakan daerah Jambi Hulu yang berstatus Kewedanaan dibawah Kabupaten Merangin dan Keresidenan Jambi Provinsi Sumatera Tengah. Sarolangun terletak di Jambi Hulu wilayah Jambi dengan dialiri beberapa Sungai. Pertempuran dalam mempertahankan kemerdekaan di Sarolangun juga memakan waktu yang cukup lama (Museum Perjuangan Jambi: 2020).

Proklamasi kemerdekaan akhirnya sampai di Kewedanaan Sarolangun disampaikan oleh pedagang-pedagang dari Bangko pada tanggal 19 Agustus 1945. Kemudian tiga hari berikutnya pad tangal 21 Agustus 1945 di rumah Wedana 
Sarolangun. Kemudian Sulaeman terjadilah rapat pengibaran Bendera merah Putih dan akan membentuk barisan pemuda perjuangan. Bendera merah putih pertama kali dikibarkan di Sekolah rakayat Pasar Sarolangun yang sekarang menajdi SD 44 (Dewan Harian Daerah Angkatan 45: 1991) adapun Peserta pertemuan Sarolangun adalah sebagai berikut: 1. Sultan Soelaiman 2. Saymsu Bahroen 3. Syarnoebi 4. H.M Chatib 5. M. Darwis dan tokoh lainya.

\section{Pola Pertempuran Kasiro-Sungai Pinang Batang Asai Menghadapi Belanda} 1949

Pertempuran di Sungai Pinang dan Kasiro Batang Asai terjadi bulan Mei 1949 Belanda mulai memasuki Sungai Pinang terjadilah pertempuran dengan TNI sektor Batang Asai yakni Sayuti Makalam. Belanda melaju ke Batang Asai melalui Dusun Selango dan Payo Sikumbang. Melihat situasi yang tidak menguntungkan semua aspek pemerintah dan TNI di Batang Asai menyingkir ketepian seberang kantor Marga di Bukit Perayun dan bermalam dan pada keesokan harinya datanglah Letnam Satu M. Thalib dan melaporkan ke Muara Siau bahwa untuk segara melakukan pertempuran gerelia di Lubuk Resam, numun gagal karena Lubuk Resam telah diduduki Belanda. Kasiro tidak ada angota TNI maka Komandan STD Menunjuk Aip A Mohd. Ali Hanifih sebagai komandan. (Dewan Harian Daerah Angkatan 45: 1991).

Pada bulan Juni 1949 pasukan Belanda dibawah pemimpin Sersan Mayor KNIL Patiwaeel masuk ke Kasiro pukul 06.00 pagi, semua pemerintahan sipil dan polisi dapat menyelamakan diri. Setalah Kasior dikuasai oleh Belanda, maka TNI dengan kukuatan 40 oeang besenjata lengkap mempersipkan penyerangan terhadap Belanda di Kasiro yang dipimpin oleh Suprapto dan mengirim pasukan Kurir di pematang Jering kepada TNI. Kemudian Sayuti Rozak mengirimkan kurir ke Suprapto namun kurir tidak pernah sampai menanyakan jam dan waktu dimulai penyerangan, akibatnya serangan terhadap Belanda Mengalami kegagalan (Dewan Harian Daerah Angkatan 45: 1991).

Kasiro sudah dalam gengaman Belanda. Adapun starategi yang dilakuakn oleh para pejuanang adalah dengan memindahkan Pemerintah Sipil ke Rantau Panjang Batang Asai, yang mendapat dukungan penuh dari wakil pesirah atau pembarab Datuk Ajib. Dalam suatu usaha merebut kembali kasiro pada tangal 8 
PERTEMPURAN KASIRO- SUNGAI PINANG BATANG ASAI MENGHADAPI AGRESI

MILITER BELANDA II DI KEWEDANAAN SAROLANGUN 1948-1949

(Supian, Lagut)

Agustus 1949 Kapten M .Kukuh menjabat sebagai komandan TNI sektor Kasiro yang bermasrkas di Muara Talang Batang Asai. Bersama dengan Sayuti Makalam, Komandan Sektor TNI Batang Asai siap mengempur Kasiro sejumlah 150 orang. Pada pagi ahrinya dapat kabar datangnya surat tentang pemberhentian tembak menembak di daerah Batang Asai. Dengan demikian Belanda bertolak dari Batang Asai dengan berdirinya Republik Indonesia Serikat 27 Desember 1949 maka Batang Asai tetap bagian dari Republik Indonesia di bawah Provinsi Sumatera Tengah. (Dewan Harian Daerah Angkatan 45, 1991).

\section{PENUTUP}

Untuk berkuasa kembali di Indonesia berbagai macam cara dilakukan oleh Belanda dalam menduduki wilayah NKRI. Kemerdekaan Indonesia 17 Agustus 1945 membuat bangsa Indonesia mati matiaan membela tumpa daranya dan terlepas dari penjajah barat.terhitung Belanda sudah dua kali melakukan ageresi militernya. Agresi Militer Belanda I dan Ageresi Militer Belanda II. Belanda melakukan penyerangan ke berbagai pelosok daerah termasuk Keresidenan Jambi. Keresidenan Jambi yang merupakan daerah Sumatera ini mendapat serangan dari Belanda ke pelosok daerah keresidenan.

Batang Asai merupakan daerah pedalaman Keresidenan Jambi kabupaten Merangin salah satu yang medapat serangan dari Militer Belanda. Sebuah Dusun yang bernama Kasiro telah diduduki Belanda pada tahun 1949 penawananpun terjadi antara pejuang pihak Indonesia Belanda. Namun dapat diatasi dengan keluarnya Surat pemberhentian tembak menembak di Batang Asai pada tahun 1949.

\section{DAFTAR PUSTAKA}

Adi Sudirman. (2014). Sejarah Lengkap Indonesia. Jakarta: Diva Press.

Bambang Suwondo. (1979). Sejarah Revolusi Kemerdekaan. (1945 1949) Daerah Jambi. Jakarta: Depdikbud.

Dewan Harian Daerah Angkatan 45.(1991). Sejarah Perjuangan Kemerdekaan RI (1945 1949) di Provinsi Jambi. Jambi: C.V Majlis Raya Offset. 
Dewan Pimpinan Cabang Legium Veteran Ri. (2009). Penyusunan Pemerintahan Sipil dan Kekuatan Bersenjata 1945-1949 Daerah Jambi: Jambi: Departemen Pendidikan Nasional.

Faisal Ismail. (2017). Panaroma Sejarah Islam dan Politik di Indonesia Sebuah Studi Komperhensif. Yokayakarta: IRCiSod.

Kuntowijoyo. (2013). Pengantar Ilmu Sejarah. Yokakarta: PT Benteng Pustaka.

Marwati dan Nugroho. (2011). Sejarah Nasional Indonesia IV. Jakarta: Balai Pustaka.

Musyrifah Sunanto. (2012). Sejarah Peradaban Islam Indonesia. Jakarta: PT Radja Grafindo Persada.

Pemprov Jambi. (2013). Profil Provinsi Jambi. Jambi: Pemerintahan Provinsi Jambi.

Sangkara. (2017). Perjuangan Angkata 66 di Jambi. Skripsi. Jambi: Program Studi Ilmu Sejarah Fakultas Ilmu Budaya Universitas Jambi.

Suhartono. (2014). Teori dan Metodologi Sejarah.Yokyakarta: Graha Ilmu.

Suwandi. (2002). Sejarah Museum Subkoss Garuda Sriwijaya di Lubuklinggau. Lubuklingau: Yayasan Subkoss Garuda Sriwijaya.

Syura Aulia. (2017). Rakyat Bungo Dalam Perang Kemerdekaan. Skripsi. Jambi: Program Studi Ilmu Sejarah Fakultas Ilmu Budaya Universitas Jambi.

Yulia Resha.(2017). Sejarah Pemekaran Kabupaten Tanjung Jabung Timur Tahun 1999 2010. Skripsi. Jambi: Program Studi Ilmu Sejarah Fakultas Ilmu Budaya Universitas Jambi. 